\title{
Exploring the Educational Concept of Sustainable Development for the Teaching of Marketing in Higher Vocational Education
}

\section{Lixiaona}

\author{
Heyuan Polytechnic, Heyuan Guangdong,517000
}

\begin{abstract}
Keywords: higher vocational colleges, marketing, sustainable development education concept
\end{abstract}

\begin{abstract}
Higher vocational education usually focuses on cultivating students' knowledge reserve and practical skills. Compared with the results of many teaching reforms, it lacks the promotion and practice of sustainable development education concepts based on "education". Aiming at the vocational marketing major, three methods of integrating sustainable development education concepts with professional teaching were proposed, namely, humanities education, vocational education and green education concepts. The results should be promoted in various vocational colleges and Popularize to achieve the essential goal of education.
\end{abstract}

\section{高职市场营销专业教学可持续发展教育理念探索}

\author{
李晓娜 \\ 河源职业技术学院，广东河源，517000
}

关键词：高职院校；市场营销；可持续发展教育理念

摘要: 高职教育通常着重于培养学生的知识储备和实践技能, 相对于多项教学改革成果而言, 缺乏“育人”为主的可持续发展教育理念推广和实践。针对高职市场营销专业, 提出了三项可 持续发展教育理念与专业教学相融合的方式, 分别是人文素养教育、职业素养教育和绿色教 育理念，该成果应当于各高职院校进行推广并普及，以实现教育的本质目标。

\section{1. 引言}

1987 年联合国世界环境与发展委员会(WCEP)向联合国提出《我们共同的未来》报告书, 把“可持续发展”定义为这样一种经济社会发展模式: 即能够满足当代人类的需求又不损害未 来人类实现其需求的机会。”1992 年联合国环境与发展大会把可持续发展作为人类发展的新 战略和新观念，认为人类应该与自然和谐发展，并为后代提供良好的生存发展空间，人类应 珍惜共有的资源环境，有节制地开采资源甚至保护资源永续存在。因此人类应当改变现有的 生活方式、消费方式和经济发展方式，注重人与自然的关系，建立新型的伙伴关系，保持人与 自然和谐统一, 人与自然和平相处。逐渐地, 可持续发展已经从关注生态与环境逐渐演变为指 导全社会经济发展的一种新理念。

教育作为培养人的社会活动，肩负着为社会发展与进步提供人才保证的重任，是劳动力 再生产的重要手段, 是科学知识再生产的必要手段。与社会发展相比, 教育要体现出超前性 和预见性，在可持续发展已经成为全人类共识和共同努力方向的今天，只有实现面向全体的 可持续发展教育，才能使教育真正成为推动社会发展与进步的手段 ${ }^{[1]}$ 。 


\section{2. 高职市场营销专业的可持续发展理念}

高职教育与本科教育的区别在于高职教育理念以培养技能注重实践为主、侧重实训实习 等课程的教学比重、企业联合培养和教育为主要培养路径、教学过程中注重引导学生在做中 学和学中做, 可见高职教育加强企业合作和学生实践是培养高技能优秀人才的重要举措。市 场营销作为经贸专业大类的一个专业方向, 在高职院校中达到了 $90 \%$ 以上的开设率, 广东省 每年毕业于市场营销专业的高职学生高达数万人，专业教育以技能培养为重点是册容置疑的 现实, 但是随着社会、人文、经济等的高速发展, 保障社会各因素协调发展已经为高职教育 的可持续发展提出了更高的要求。本文将从人文素养教育、职业素养教育和绿色教育理念三 方面对可持续发展教育理念如何应用于高职院校的市场营销专业教学进行探讨。

\section{1 人文素养教育}

人文素养指的是个人由于具备了充分的人文知识而展现出来高度的人文精神，这种人文 精神体现在心理健康、价值观高尚、谈吐文明、自信豁达和积极进取等丰富的个人品质。由 于具备了高尚优秀的品行, 使得个人的生活和工作都可以达到和谐平衡 ${ }^{[2]}$ 。高职学生由于相对 学历较低, 并且对未来持有某种程度的不乐观情绪, 因此在教学过程中, 院校和教师应当重 视提升高职学生的心理修养和自我认可等方面的培育, 提升学生心理素质、提高自我认可、 加强自信心和鼓励积极进取等。以市场营销专业为例, 由于其毕业生未来的工作多属于销售 类的一线工作, 因此训练其与人沟通的能力为核心培养目标。在教学过程中, 教师可以将心 理方面的培育融入专业课程的实施中, 使学生在学习专业技能的过程中潜移默化地提升其心 理素质，增强其人文修养。

表 1 市场营销课堂教学活动与人文素养教育

\begin{tabular}{|c|c|}
\hline 教学活动 & 融入人文素养的手段 \\
\hline 案例学习 & $\begin{array}{l}\text { 选取高度体现积极进取精神或者富含文化因素的案例作为学习素材, 使学生在学习 } \\
\text { 案例中体现的技能过程中, 领会案例角色坚忍不拔、灵活应变和积极思考的精神, } \\
\text { 或者在学习案例技能时, 可学习到不同时代不同地区的文化思想, 加强其文化素 } \\
\text { 养。 }\end{array}$ \\
\hline 小组讨论 & $\begin{array}{l}\text { 鼓励小组成员各抒己见、大胆思考、勇于表达，引导小组组长做好管理和领导团队 } \\
\text { 的工作，在实践中教会小组成员如何处理不同意见、如何做到分工合理、如何最大 } \\
\text { 程度发挥团队力量等。 }\end{array}$ \\
\hline 角色扮演 & $\begin{array}{l}\text { 鼓励同学们在进行角色扮演时, 注意语言表达方式、待人接物礼仪、端正社会心理 } \\
\text { 等, 切忌自私自利、谎言欺骗、弄虚作假、鱼目混珠等不端行为。 }\end{array}$ \\
\hline 测验考试 & $\begin{array}{l}\text { 向学生灌输作弊破坏诚信、抄袭导致贪婪的思想, 杜绝抄袭、夹带、偷看等作弊行 } \\
\text { 为, 作弊意味着不劳而获的贪便宜心理, 做人做事千万不可持有该心理, 否则将会 } \\
\text { 导致不可控的恶劣后果, 使学生持有“宁丢一分不丢品格”的价值观。 }\end{array}$ \\
\hline 课堂考勤 & $\begin{array}{l}\text { 考勤过程难免会出现冒名顶替等行为, 教师应当杜绝此类行为, 教会学生遵守校园 } \\
\text { 规则, 尊重课堂秩序, 不应当以个人私事耽误学业、更不应当养成懒惰倦急的生活 } \\
\text { 习惯, 尊重校园规则才能学会尊重社会规则, 尊重社会规则才能在未来就业和人生 } \\
\text { 中占有一席之地。 }\end{array}$ \\
\hline
\end{tabular}

\section{2 职业素养教育}

职业素养指的是就业过程中，个人所需具备的职业技能、品质道德、综合素质等，他们 是一种合格的语言表述和行为规范方式，良好的职业素养能够提升工作效率、展现良好的品 质修养。职业素养主要包括三个因素：职业信念、职业知识技能和职业行为习惯。良好的职 业信念表现为爱岗、敬业、忠诚、奉献、正面、乐观、用心、开放、合作及始终如一等个人品 质; 职业知识技能是为了完成一项工作所必须具备的相关理论知识和熟练的操作能力，不同 职业需要不同的职业知识技能, 目前高等教育主要就是培养大学生的职业知识技能; 职业行 为习惯是在工作实践中展现出的行为方式，包括言谈举止、沟通方法和礼仪礼节等，良好的 
职业行为习惯可以展现专业的精神面貌 ${ }^{[3]}$ 。

市场营销专业的核心课程包括《市场营销学》、《推销实务》、《营销商务谈判》、《客户服 务实务》、《营销策划》、《市场调查与预测》等, 根据以上课程的教学大纲来看, 课程设置和 教学主要侧重于职业知识技能的培养, 多数课程的开展并未涉及提升学生的职业信念和职业 行为习惯。因此每一门专业课程都应当依据职业素养这一可持续发展的人才培养需求改进课 程, 使得学生在学习知识和技能之余, 还可以增强职业信念和形成良好的职业行为习惯。

表 2 市场营销专业核心课程职业素养培育

\begin{tabular}{|l|l|l|}
\hline \multicolumn{1}{|c|}{ 课程名称 } & \multicolumn{1}{|c|}{ 职业信念 } & \multicolumn{1}{c|}{ 职业行为习惯 } \\
\hline 市场营销学 & 创新、严谨、开放、包容 & 善于发现问题、积极解决问题、统筹兼顾 \\
\hline 推销实务 & 亲和、沟通、博学、敏感 & 擅长沟通、积极挖掘需求、创造性地解决方案 \\
\hline 营销商务谈判 & 善谋、灵敏、善谈、说服 & 擅长分析利弊、创造性地解决矛盾、谈吐清晰 \\
\hline 营销策划 & 创新、包容、发现、进取 & 具备创新精神、组织协调能力、善于沟通 \\
\hline 市场调查与预测 & 细心、认真、严谨、积极 & 具备严谨的考察精神、认真负责务实 \\
\hline 客户服务实务 & 随和、关怀、包容、善意 & 擅长做心理疏导、疏解工作压力和乐于助人 \\
\hline
\end{tabular}

\section{3 绿色教育理念}

\section{（1）绿色文化教育}

绿色文化指的是人与自然协调发展、和谐共进，能使人类实现可持续发展的目标，以崇 尚自然、保护环境、促进资源永续利用为基本特征, 是以环境意识为核心的一种文化。新时 期弘扬绿色文化, 就是要树立与构建和谐社会相适应的环境理念和文明发展观, 不断丰富和 满足人们、向往自然、保护自然和回归自然的文化需求，促进资源环境与经济社会的可持续 发展, 因此树立和弘扬绿色文化是构建和谐社会的必然要求。

高职学校和教师应当提高学生的绿色消费意识与行为, 不断增强全校师生的环境意识、 绿色理念和法制观念, 提高校园的绿色文明素养。应当及时宣传和表扬绿色校园建设过程中 涌现出来的先进事迹, 提高师生对绿色校园建设的知晓率和认知度, 增强师生建设绿色校园 的参与意识，形成全民参与绿色校园建设的良好氛围 ${ }^{[4]}$ 。

院校层面可在专业、学院、学校范围内定期举办绿色文化主题知识竞赛和辩论赛等，以 传扬绿色文化为目标, 以多种学生喜闻乐见的形式开展, 内容多种多样, 形式不拘一格。在 市场营销专业教学中, 教师应在授课过程中主动积极地向大家灌输环境保护和节约资源的知 识, 例如, 把绿色文化理念编写入人才培养方案, 将绿色文化作为考核学生的学习成果之一, 在课堂上注意利用机会传输绿色文化概念和意义等。

(2) 课堂绿色教育

教师的教学活动与学生的学习活动主要空间为校园和教室, 在教室展开的教学活动需要 使用多种教学手段和工具, 例如黑板、白板、纸张、实物道具、摄录器材、实验器材等, 应用 道具和工具开展教学的活动给践行课堂绿色教育提供了很大的空间。例如可以将传统的黑板 粉笔改为白板教学, 这样可减少粉尘污染, 使得课堂空气和环境大有改观; 还可以减少纸质 教学文件和耗材的使用, 尽量使用电子资源; 教师和学生提高节约能源意识, 下课后及时主 动关闭多媒体设备、空调、风扇等电器设施; 学生在课外时间多使用电子图书和电子文档学 习，学会垃圾分类，减少塑胶制品的使用，减少一次性餐具的使用等等。

\section{3. 总结}

可持续发展理念已经成为人类社会发展的共识，作为社会重要传播途径的高职教育理应 担负起应尽的责任, 可持续理念融入高职教育于社会有利、于学生有利, 本文以市场营销专 业的可持续发展实践进行探讨的成果可以推广到其他各类专业, 应用到更多的专业教学实践。 


\section{References}

[1] Dou Jin, Zhang Min, etc., The theory and practice of school education, Northeast Normal University Press, 2014.02, p28

[2] Wang Qi, Research on Regional Education Quality Monitoring System, Zhejiang University Press, 2015.09, p57

[3] Editor-in-chief, Theoretical Learning and Practical Innovation, Central Compilation and Translation Press, 2012.04, p135

[4] Zhang Zhiguang and others, Theory, Strategy and Application of Green China, China Environmental Science Press, 2010.11, p466 